\title{
Evaluation on ecological footprint of ethnic cultural tourism industry in Yunnan province of China
}

\author{
H.Y. XIE ${ }^{1,2}$,W.L. YAN ${ }^{3}$, J.D.YI ${ }^{4}$ \\ ${ }^{1}$ College of Travelism and Geography Sciences, Yunnan Normal University, Kunming, China \\ ${ }^{2}$ College of Pschology of Education,Neijiang Normal University,Neijiang, China \\ ${ }^{3}$ College of Foreign languages, Yunnan University of Finance and Economics, Kunming, China \\ ${ }^{4}$ Key Laboratory of Educational Informalization for Nationalities,Ministry of Education, Yunnan \\ Normal University, Kunming, China
}

KEYWORD: Tourism ecological footprint (TEF); Tourism ecological capacity; Tourism ecological;Deficit / Surplus

ABSTRACT: Based on the introduction to the concept and calculation method of tourism ecological footprint, the tourism ecological footprints of 8 minority autonomous prefectures in Yunnan province are calculated and analyzed according to the data of the statistical yearbooks of Yunnan province in 2014. The results turn out the tourism ecological footprints in Wenshan Zhuang Autonomous Prefecture and Nujiang Lisu Autonomous Prefecture are status of strong surplus; Xishuangbanna Dai Autonomous Prefecture and Diqing Tibetan Autonomous Prefecture are weak surplus, while the other four minority autonomous prefectures are in status of deficit. And the average tourist ecological footprint of 8 minority autonomous is up to $1725 \mathrm{hm}^{2}$, which is rather high relative to the total GDP of Yunnan tourism ecological footprint, the data shows that ethnic minority cultural tourism in those eight minority autonomous prefectures is relative well-developed, but the tourism ecological footprint deficit confirms that the human tourism load stays beyond the regional tourism biocapacity, and the regional tourism natural ecosystem is under great pressure of human tourism activities.

\section{INTRODUCTION}

In the study of sustainable development, the quantitative measurement is one of the important methods [1]. It is a fundamental development of maintaining the stock of natural assets for the sustainable development of human society. While the core of sustainable development research is to use the quantitative assessment to measure the natural use of human beings, and weather those natural use is under the natural production capacity. In China, the sustainable development strategies and the western development policy have huge impaction on the economy, demographic and resources of western minority areas, while the ecosystem is becoming imbalance because of the human activity increase.

\section{Ecological footprint}

The ecological footprint and calculating analysis have been put forward and developed by the Canadian ecological economist William E.Rees and his student Mathis Wackernagel and Wackernagel since 1990s, which also known as ecological footprint [1]. The measure scale of ecological footprint can be a country, a city, an industry or a person. In China, the introduction of ecological footprint was first applied by Zhongmin $\mathrm{Xu}$ in his article "The Calculation and Analysis of Ecoligical Footprints of Gansu Province". [2]

Tourism ecological footprint Theory is began by Hunter. Hunter is the first person to propose the concept of tourism ecological footprint in 2002, and the significance of sustainable development of tourism ecological footprint is also discussed by him. [3] In China, Jianchao Xi [4], Jinhe Zhang [5] discuss on the tourism ecological footprint. Tourism ecological footprint refers to the total area of ecologically productive land and water occupied exclusively to produce all the resources consumed by tourist in the process of traveling. Tourism ecological footprint is actually an integrated parameter which not only contains the resumed land and water in the tourism activities etc., but also includes waste absorption. So the impact of tourism and tourism activities on the environment can be fully measured by tourism ecological footprint. $[6,7,8]$ At the same time, the profound meaning of Eco- 
tourism activities consumed can be fully measured.

This paper takes 8 autonomous prefectures of Chuxiong, Honghe, Wenshan, Xishuangbanna, Dali, Dehong, Nujiang, Diqing as the study of tourism ecological footprint in Yunnan province, in order to provide theoretical guidance for the sustainable development of tourism in Yunnan, the regional ethnic cultural tourism Quantitative Evaluation of sustainable development empirical research is on.

\section{Tourism ecological footprint}

In the calculation of Eco-tourism indexes, all kinds of resources and energy consumption are classified as types of biologically productive area, such as farmland, grassland, woodland, building land, fossil fuels and water. [3, 7, 8] Due to the different ecological productivity of 6 types, it needs to multiply various types of biologically productive area by the corresponding equivalence factor to get the tourism ecological footprint and tourism ecological capacity. While the equivalence factor is got by one average biological production area divided by all types of average biological production areas. According to this formula, all kinds of equivalence factors are as follows: farmland and building land are 2.8, woodland and fossil energy land is 1.1 , grassland is 0.5 , and water is $0.2[3,4,7$, and 8].

\section{Six Eco-tourism indexes and Models}

In this paper, according to the tourist consumption structure, the Eco-tourism indexes are divided into transportation, catering, accommodation, and shopping, sightseeing, entertainment:

The ecological footprint of transportation consists of built-up area of traffic facilities and the transport energy consumption in the process of tourism, such as airports, highways, railways, cable and other transportation facilities, as well as fuel energy consumed; therefore the biologically productive area includes fossil fuels and build-up area.

\section{$\mathrm{TEF} 1=\sum(\mathrm{S} 1 \times \mathrm{Ri})+\sum(\mathrm{Nj} \times \mathrm{Dj} \times \mathrm{Cj} / \mathrm{t})$}

Where $S_{1}$ is the area of varieties of transportation facilities; Ri is the $i^{- \text {th }}$ utilization of tourist transport facilities; $\mathrm{Nj}$ is the tourist numbers who select the $\mathrm{i}^{\text {-th }}$ transport facilities; $\mathrm{Dj}$ for the average travel distance that tourist select the transport facilities, while $C_{j}$ for the transport energy consumption that the transport facilities consume; $t$ is the corresponding energy equivalence factors.

The ecological footprint of accommodation is mainly estimate the built-up area of all kinds of hotels, guest houses and other accommodation facilities, as well as the energy consumed of tourists during the accommodation, including the air conditioning, lighting, energy and other washing.

\section{$\mathrm{TEF} 2=\sum(\mathrm{Ni} \times \mathrm{S} 2)+\sum(365 \times \mathrm{Ni} \times \mathrm{Ki} \times \mathrm{Ci} / \mathrm{t})$}

Where $\mathrm{Ni}$ is the beds' numbers of one accommodation facilities, S2 is the built-up area of each bed of accommodation facilities; Ki for $\mathrm{i}$-th annual average room occupancy rate of accommodations; $\mathrm{Ci}$ is the energy consumption of each accommodation and per bed; $t$ is the corresponding energy equivalence factors.

The ecological footprint of tourism catering is mainly calculate the built-up area of food, meat, vegetables, fruits and other catering facilities that tourists consume in the tourism area, as well as the corresponding ecologically productive area of all kinds of food, which includes the farmland, grassland, water area and woodland.

$$
\mathrm{TEF}_{3}=\sum \mathrm{S}+\sum(\mathrm{N} \times \mathrm{D} \times \mathrm{Ci} / \mathrm{pi})+\sum\left(\mathrm{N} \times \mathrm{D} \times \mathrm{E}_{\mathrm{j}} / \mathrm{t}_{\mathrm{j}}\right)
$$

Where $\mathrm{S}$ is built-up area of all the variety of dining facilities; $\mathrm{N}$ is tourist numbers; $\mathrm{D}$ for the average days of tourist travelling; $\mathrm{C}_{\mathrm{i}}$ for the $\mathrm{i}$-th daily food consumption of tourists; $\mathrm{p}_{\mathrm{i}}$ is the $\mathrm{i}$-th average productivity of food organisms; $\mathrm{E} j$ for the $\mathrm{j}^{\text {-th }}$ daily energy consumption of tourists; $\mathrm{t}_{\mathrm{j}}$ is the corresponding energy equivalence factors of energy $\mathrm{j}$.

The ecological footprint of shopping refers to the tourism productions that tourists bought, corresponding to the biological resources, industrial products, energy consumption. The biologically productive lands are farmland, grassland, water, woodland, fossil fuel land and building land.

$\mathrm{TEF}_{4}=\sum \mathrm{S}_{4}+\sum[(\mathrm{Rj} / \mathrm{Pj}) / \mathrm{Gj}]$

Where $S_{4}$ is the built-up area of commodity production and sales facilities; $R_{j}$ for spending of the $j$ th commodity production; $P_{j}$ is average price of the $j^{\text {-th }}$ commodity production in the tourism area; $g_{j}$ is the average productivity of the $\mathrm{j}^{\text {-th }}$ commodity production. 
The ecological footprint of entertainment includes the built-up area of recreational facilities and the corresponding energy consumption. This paper refers to the built-up area of large outdoor entertainment places, like theme parks, golf courses, etc.

$\mathrm{TEF}_{5}=\sum \mathrm{S}_{5}$

Where $S_{5}$ is the built-up area of outdoor recreational facilities.

The ecological footprint of Sightseeing is mainly calculating the built-up area of natural attractions and cultural attractions, corresponding to farmland, grassland, water, woodland and building land and so on.

$\mathrm{TEF}_{6}=\sum \mathrm{S}_{6}$

Where $S_{6}$ is the built-up area of tourism attractions.

The size of the ecological footprint can be drawn through the final summation of 6 indexes, which is the formula (7), where $\mathrm{TEF}_{7}$ is the total ecological footprint.

The formula of tourism ecological capacity is following:

$\mathrm{TEC}_{7}=\mathrm{EC} \times \mathbf{r}$

$\mathrm{tec}_{7}=\mathrm{TEC} / \mathrm{TN}$

Where $r$ for GDP contribution of tourism; TEC7 is tourism ecological capacity; EC for the ecological capacity of each region; $\mathrm{TN}$ is the total number of tourists, tec 7 is the average tourism ecological capacity.

\section{Evaluation of TEF in Yunnan}

Because of the largest minority province, Yunnan is one of key areas in the protection of ecological areas in China. However, the conflicts between people and the land are becoming more and more prominent with the development of tourism, a series of ecological destruction and degradation are appeared. It not only has an important significance for Yunnan to study the utilization of natural resources, the human production pressure on the regional ecosystem and quantitative measures to the status of regional sustainable development, but also has a huge significance on the policy of sustainable development in China.

\section{Calculation on TEF in Dali prefecture}

According to the data of the statistical yearbooks of Yunnan province in 2014, the tourism ecological footprint of $\mathrm{Yi}$ autonomous prefecture of Dali is calculated and analysis by the method of 6 tourism ecological footprint indexes. There are 2 parts of tourism ecological footprint, (1)biological resource consumption; (2) energy consumption. Meanwhile, in the process of calculating the consumption of biological resource consumption and energy consumption, trade adjustment needs to be considered.

Consumption of biological resources section includes agricultural products, animal products, forest products, and fruit and wood while the energy consumption is calculated based on the energy footprint information of coal, coke, fuel oil, crude oil, gasoline, diesel fuel and electricity, when the consumption of fossil energy is calculated, it is converted to land area. The average tourism ecological footprint of Yi autonomous prefecture is got through the proportion of different types of tourism footprint multiplied by the equivalence factors (table 1).

From Table 1, it can be seen that the tourism ecological footprint of Yi Autonomous Prefecture is $1.1858 \mathrm{hm}^{2}$, which shows that the status of tourism is not sustainable in Dali.

In Yi Autonomous Prefecture of Dali, there have $42.76 \times 10^{4}$ farmland; $66.9 \times 10^{4}$ forestland, $12.19 \times 10^{4}$ grassland, and $10.22 \times 10^{4}$ water area, the per capita amount of biologically productive area of various types of data are shown in Table 2 , which is the biologically productive area provide for the tourists in Dali.

According to the table 2, the average tourism ecological capacity is calculated by the biologically productive area multiplied by equivalence factors and yield factors, as shown in Table 3 . 
Tab 1 Traveling ecological footprint of Dali in Yunnan Province (2013)

\begin{tabular}{|c|c|c|c|c|}
\hline Terms & Land types & $\begin{array}{l}\text { TEF } \\
\left(\mathrm{hm}^{2} / \text { cap }\right)\end{array}$ & $\mathrm{Ef}$ & $\begin{array}{l}\text { aTEF } \\
/\left(\mathrm{hm}^{2} / \text { cap }\right)\end{array}$ \\
\hline \multirow[t]{2}{*}{ Built-up area } & highway & 4926 & & $0.42 \times 10^{-3^{x}}$ \\
\hline & rai & 273 & & $0.93 \times 10^{-6}$ \\
\hline Transport & aviation & 19 & 2.8 & $1.61 \times 10^{-6}$ \\
\hline Total & & 5219 & & $0.99 \times 10^{-3}$ \\
\hline \multirow{3}{*}{\multicolumn{2}{|c|}{$\begin{array}{r}\text { Fossil fuel area highway } \\
\text { railway } \\
\text { aviation }\end{array}$}} & 198221 & & $16.41 \times 10^{-3}$ \\
\hline & & 40358 & & $9.03 \times 10^{-3}$ \\
\hline & & 24811 & 1.1 & $2.37 \times 10^{-3}$ \\
\hline \multicolumn{2}{|l|}{ Total } & 263390 & & $27.82 \times 10^{-3}$ \\
\hline \multicolumn{2}{|l|}{ Built-up area } & 1024 & 2.8 & $0.93 \times 10^{-3}$ \\
\hline \multicolumn{2}{|c|}{ Fossil fuel area } & 6973 & 1.1 & $0.72 \times 10^{-3}$ \\
\hline \multicolumn{2}{|l|}{ Farmland } & 2260 & 1.1 & $2.08 \times 10^{-4}$ \\
\hline \multicolumn{2}{|l|}{ Grassland } & 32559 & 0.5 & $2.70 \times 10^{-3}$ \\
\hline \multirow[t]{3}{*}{ Catering } & woodland & 229 & 1.1 & $0.21 \times 10^{-4}$ \\
\hline & Fossil fuel area & 2395 & 1.1 & $1.98 \times 10^{-4}$ \\
\hline & Water area & 110 & 0.2 & $0.08 \times 10^{-4}$ \\
\hline Sightseeing & Built-up area & 8246 & 2.8 & $0.72 \times 10^{-3}$ \\
\hline & & 13 & 1.1 & $1.01 \times 10^{-2}$ \\
\hline farm & & 11 & 1.1 & $5.15 \times 10^{-3}$ \\
\hline Entertainm & Built-up area & 892.91 & 2.8 & $0.45 \times 10^{-3}$ \\
\hline
\end{tabular}

$(\mathrm{TEF}=$ Tourism Ecological Footprint; $\mathrm{Ef}=$ Equivalence factor; Atef= Average Tourism Ecological Footprint $)$

Tab2 Biologically productive area of Dali in Yunnan province

\begin{tabular}{cccc}
\hline PAtype & $\begin{array}{c}\text { Area } \\
/\left(10^{4} \mathrm{hm}^{2}\right)\end{array}$ & $\begin{array}{c}\text { Percent } \\
(\%)\end{array}$ & $\begin{array}{c}\text { APA } \\
/\left(\mathrm{hm}^{2} / \text { cap }\right)\end{array}$ \\
\hline Farmland & 42.76 & 6.02 & 0.01 \\
Woodland & 66.90 & 9.64 & 0.15 \\
Grassland & 12.19 & 12.67 & 0.08 \\
Water area & 10.22 & 1.30 & 0.01 \\
\hline
\end{tabular}

Tab 3 Traveling ecological

ing ecological capacity of Dali in Yunnan province (2013)

footprint and travel-

\begin{tabular}{lccc|lccc}
\hline \multicolumn{4}{c|}{ ATEF } & \multicolumn{4}{|c}{ ATEC } \\
\hline Lt & Aa & Ef & Ea & Lt & Aa & Ef & Ea \\
\hline farm & 0.19 & 2.8 & 0.31 & farm & 0.15 & 1.66 & 0.68 \\
grass & 0.60 & 1.0 & 0.30 & grass & 0.09 & 0.19 & 0.01 \\
wood & 0.04 & 1.1 & 0.04 & wood & 0.14 & 0.91 & 0.14 \\
Fossil & 0.46 & 1.1 & 0.51 & fossil fuel & 0.12 & 1.25 & 0.90 \\
built-up & 0.19 & 2.8 & 0.02 & built-up & 0.02 & 1.66 & 0.05 \\
Water & 0.02 & 0.2 & 0.01 & water area & 0.01 & 1.00 & 0.01 \\
ATEF & & & 1.18 & ATEC & & & 0.73 \\
\hline
\end{tabular}

In the table 3, it shows that the tourism ecological footprint and the tourism ecological capacity are respectively $1.1858 \mathrm{hm} 2$ and $0.7328 \mathrm{hm} 2$, so the average tourism ecological deficit is $0.4530 \mathrm{hm} 2$.

\section{Results and analysis of TEF}

According to the calculating method of tourism ecological footprint and the above calculating process of $\mathrm{Yi}$ autonomous prefecture in Dali, the actual calculation on the tourism ecological footprint of 8 minority autonomous prefectures are reached from the data of the statistical yearbooks of Yunnan province in 2014, as shown in Table 4. 
Tab 4 Traveling ecological footprints and traveling ecological capacities of 8 minority autonomous prefectures in Yun-

\begin{tabular}{|c|c|c|c|c|c|c|}
\hline Prefectures & $\begin{array}{l}\text { numbers ATEF } \\
/\left(10^{4} / \text { cap }\right)\end{array}$ & $\begin{array}{c}\text { ATEC } \\
/\left(\mathrm{hm}^{2} / \mathrm{cap}\right)\end{array}$ & $\begin{array}{c}\text { ATEF } \\
/\left(\mathrm{hm}^{2} / \mathrm{cap}\right)\end{array}$ & $\begin{array}{r}\text { Total } \\
\left(\mathrm{hm}^{2}\right)\end{array}$ & $\begin{array}{l}\text { ATEF } \\
\text { cap) }\end{array}$ & $\begin{array}{l}\text { AGDP } \\
\text { / (mil- }\end{array}$ \\
\hline \multicolumn{7}{|l|}{ lion $/ \mathrm{hm}^{2}$ ) } \\
\hline Chu Xiong & 1240 & 0.9 & 0.3 & -0.5 & -1027 & 1815 \\
\hline Hong $\mathrm{He}$ & 1840 & 1.0 & 0.5 & -0.4 & -1371 & 1038 \\
\hline Wen Shan & 830 & 0.5 & 0.9 & 4.6 & 607 & 3849 \\
\hline $\mathrm{Ban} \mathrm{Na}$ & 3012 & 2.3 & 2.4 & 0.1 & -2037 & 465 \\
\hline Da Li & 3240 & 1.1 & 0.7 & -0.4 & -1805 & 1529 \\
\hline De Hong & 1939 & 1.0 & 0.4 & -0.5 & -1367 & 1836 \\
\hline $\mathrm{Nu}$ Jiang & 610 & 0.3 & 0.9 & 5.9 & 904 & 2603 \\
\hline Di Qing & 4641 & 1.8 & 1.9 & 0.1 & -2239 & 671 \\
\hline Total & 18355 & 1.1 & 1.0 & -0.1 & -8335 & 1725 \\
\hline
\end{tabular}

From the Table 4, it can be seen that the tourism ecological footprint of Wenshan Zhuang autonomous prefecture and Nujiang Lisu autonomous prefecture are strong surplus, which the first tourism ecological footprint is up to $4.6100 \mathrm{hm}^{2}$, the other is up to $5.9810 \mathrm{hm}^{2}$; while the developed-tourism autonomous prefectures, like Xishuangbanna autonomous prefecture and Diqing autonomous prefecture, the tourism ecological footprint of those 2 prefectures are status of weak surplus, $0.0821 \mathrm{hm}^{2}$ and $0.1019 \mathrm{hm}^{2}$ respectively. The other 4 minority autonomous prefectures are all deficit.

\section{TEF and sustainable development}

From the calculating results of tourism ecological footprint of 8 minority autonomous prefectures in Yunnan, the following conclusion can be drawn:

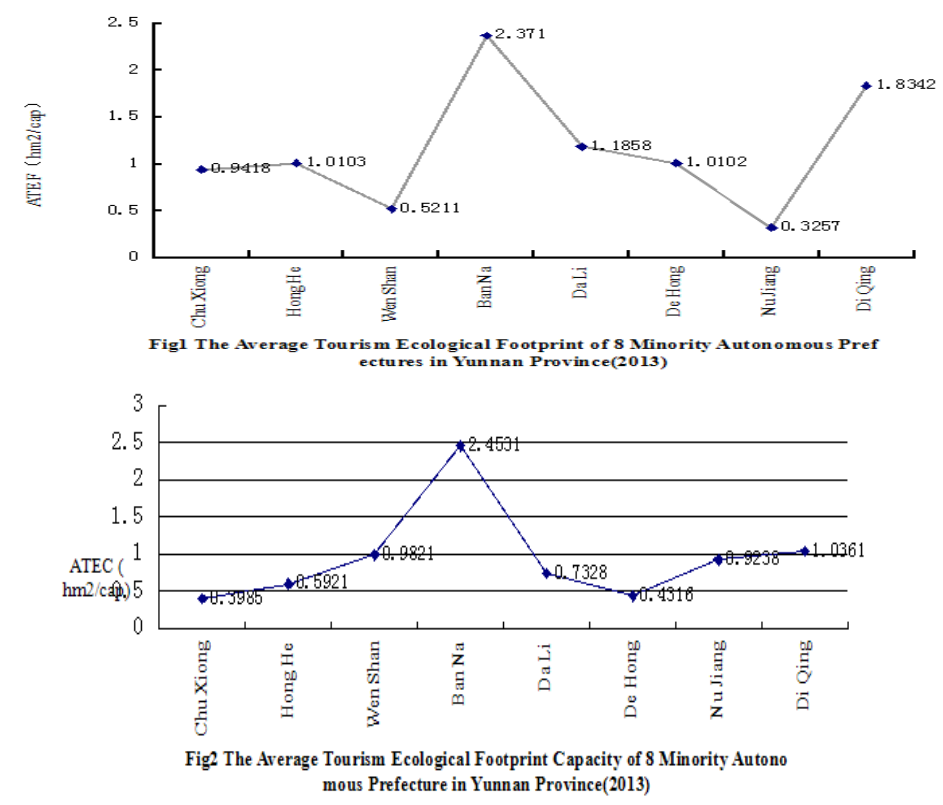

In the 8 minority autonomous prefectures, the average tourism ecological footprint of Wenshan Zhuang autonomous prefecture is $0.5211 \mathrm{hm}^{2}$, of which it is lower than the tourism ecological capacity $0.9821 \mathrm{hm}^{2}$, while the TEF of Nujiang Lisu autonomous prefecture is $0.3257 \mathrm{hm}^{2}$, of which it is also lower than the TEC $0.9328 \mathrm{hm}^{2}$, so the tourism of those 2 prefectures are statues of sustainable development in Yunnan. The other 2 autonomous prefectures, like Xishuangbanna and Diqing, though the tourism of those 2 prefectures are well-developed, the tourism ecological footprint of them are weak surplus, $2.3710 \mathrm{hm}^{2}$ and $1.8342 \mathrm{hm}^{2}$ respectively; of which they are all slightly lower than theirs tourism ecological capacity, so the tourism of those 2 prefectures are weak sustainable development. And other 4 autonomous prefectures, the TEF are all higher than the TEC, so they are status of unsustainable development.

(2) From the view of $0.477 \mathrm{hm}^{2}$ ecological value of Yunnan in 2001 , the average tourism ecological footprint of Nujiang Lisu autonomous prefecture is $0.3257 \mathrm{hm}^{2}$, which it is lower than the average ecological value of Yunnan, so the tourism status is sustainable development. 


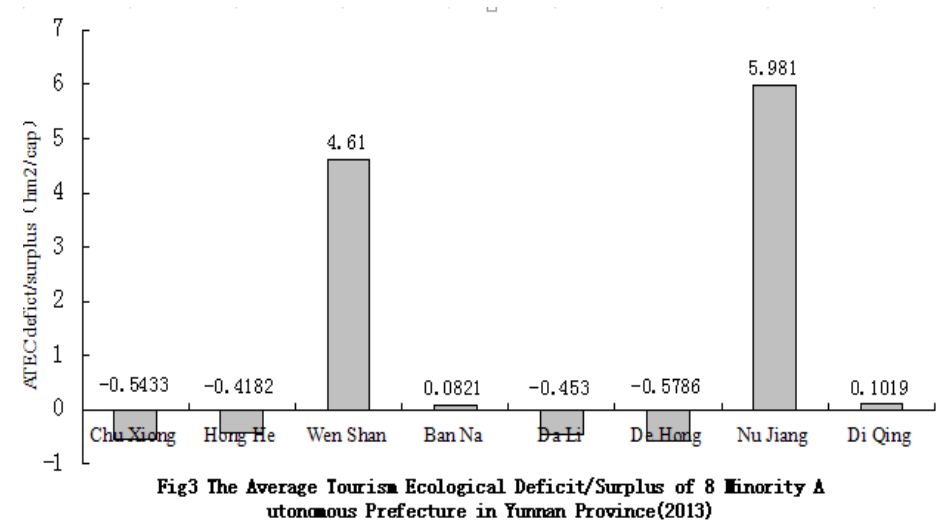

(3) In particular, there are 2 prefectures, the Xishuangbanna Dai Autonomous Prefecture and Diqing Tibetan Autonomous Prefecture, although the tourism develops relatively well in these two states, the average ecological tourism are in surplus, those tourism ecological footprint are slightly lower than the tourism ecological capacity, they are statues of weak sustuainable development. The reason can be explained that the rapid tourism development of Xishuangbanna Dai Autonomous Prefecture and Diqing Tibetan Autonomous Prefecture promote the process of the local environmental protection. Because the Tourism development needs a good background of the ecological environment, so it also increases the awareness of the local government to protect the ecology and environment.

(4) The average tourism ecological footprint of 8 Autonomous Prefectures is $1.1500 \mathrm{hm}^{2}$ in Yunnan, so the average ecological deficit is $0.0937 \mathrm{hm}^{2}$, while the ecological footprint deficit of the total population in 8 autonomous prefectures reaches $18355.91 \times 10^{4} \mathrm{hm}^{2}$, which shows that if the ecological balance and weak development want to be on, it must be has the $18355.91 \times 10^{4} \mathrm{hm}^{2}$ biological productive area.

\section{Million GDP of TEF.}

The million GDP of 8 autonomous prefectures is got by the total tourist numbers divided by the total national GDP, as shown in the Table 4. The larger of the million GDP, it indicates that the lower of the biologically production. So it can be seen from the Table 4 , the footprint demanding of 8 minority autonomous prefectures is relatively large, of which the million GDP of Wenshan Zhuang autonomous prefecture and Nujiang Lisu autonomous prefecture are rather large, it also reflect the tourism ecological footprint of each prefecture has close relationship with the natural status, the land productivity and regional economic development.

Form the table 4, it can be seen that the average tourism ecological footprint is $1725 \mathrm{hm}^{2}$; it is rather high in the million GDP of TEF in Yunnan. Because of the well-developed tourism on the ethnical culture, and the ethnical cultural tourism is key of their tourism, so it can attract many tourists.

\section{Conclusions and Discussion}

In this empirical study, it may have the following factors to impact the calculation and evaluation of the results of tourism ecological footprint indicators:

(1) The data for calculating the tourism ecological footprint is from the statistical yearbooks of Yunnan province in 2014, which belong to the statistics, the validity and credibility of it is directly affect the calculating results, thereby it also affect the calculation of tourism ecological capacity in each prefecture, so it requires the accurate statistics. So in the assessment of tourism ecological footprint indexes, the accurate statistic is the key.

(2)In this paper, the equivalence factor has a direct impaction on the calculating results of the tourism ecological footprint, there has a unified equivalence factor in the international arena, but it needs different data of different biologicalproductive area in every area. If each area is absence of the biologically productive factor, it will affect the productive factor of all regions; accordingly it will make the calculating errors of the regional tourism ecological capacity.

(3)In this paper, because of the 6 indexes of transport, catering, accommodation, sightseeing, entertainment and shopping, it can get the quantitative research of the tourism ecological footprint model of 8 minority autonomous prefectures in Yunnan, however, the lack oftourism information increase the difficulty of calculating the TEC, which take an alternative calculation method, assuming 
method that is only an expedient measure, so it does not reflect the impact of tourism activities on the ecological environment to the maximum extent.

It should be noted that tourism ecological footprint model is an analysis method based on the status of static data, the calculating results can not reflect the future trend, and the conclusions has the character of instantaneous. The collecting process of data is rathercumbersome and complex, which increase the difficulties of study, in order to study the tourism sustainable development of those 8 minority autonomous prefectures better, it need to make more efficient and meticulous work on the collection of data tracking.

\section{ACKNOWLEDGEMENT}

This work was supported by Soft Science Program of China (2013GXS4D149), Ministry of Education, Humanities and Social Sciences Project (12YJCZH053), Minority Native Culture of Quality Engineering Projects in Yunnan.

\section{References}

[1] Zh.Q.Zhang, Ch.Q.Sun, and G.D.Cheng et al.Advance in Earth Sciences, Vol. 14(1999),p. 589595.

[2]Zh.M.Xu, Zh.Q. Zhang, and G.D. et al. Geographical Sciences, Vol. 55(2000), p. 607-616

[3] Hunter C. Development and Sustainability, Vol.4(2002),p.72

[4]J.Ch.Xi,Q.Sh.G, and Sh.K.Cheng et al. Natural Resource Sciences, Vol. 19(2004)p. 224-229.

[5]J.H.Zhang, J.Zhang. Geographical Sciences, Vol.59(2004),p. 763-771.

[6]G.H.Yang, P. Li. Tourism Newspaper, Vol. 22(2007),p. 54-58.

[7] G.J.Fu. Resource Science, Vol. 28(2006),p. 145-151

[8]G.H.Yang,P.Li.EcologicalScience, Vol.25(2005),p. 1475-1480.

[9]WackernagelM, Onisto L, Bello P et al. InternationalCouncil for Local Environmental Initiatives, Toronto. 1997.

[10]WackernagelM, Onisto L, Bello P et al. Ecological Economics, Vol. 29(1999),p. 375-390. 